\title{
A preoperative evaluation of a giant mediastinal tumor using a novel three-dimensional cinematic rendering visualization method
}

\author{
Rui Wang ${ }^{1}$, Jia-Yi $\mathbf{L i}^{2}$ \\ ${ }^{1}$ Department of Radiology, The Third Affiliated Hospital of Kunming Medical University, Yunnan Cancer Hospital/Center, Kunming, China; \\ ${ }^{2}$ Department of Colorectal Surgery, The Third Affiliated Hospital of Kunming Medical University, Yunnan Cancer Hospital/Center, Kunming, \\ China
}

Correspondence to: Rui Wang. No. 519 Kunzhou Road, Yunnan Cancer Hospital/Third Affiliated Hospital of Kunming Medical University, Kunming 650118, China. Email: wangrui.98k@qq.com.

Submitted Oct 15, 2020. Accepted for publication Apr 13, 2021.

doi: 10.21037/qims-20-1161

View this article at: http://dx.doi.org/10.21037/qims-20-1161

Mediastinal tumors are a group of heterogeneous embryonic dysplasia and neoplastic diseases with different prognoses and treatment methods. They develop slowly, and $40-50 \%$ of cases are asymptomatic for a long time (1). Clinically, tumors appearing in and around the mediastinal cavity are uncommon and occasionally found by medical imaging (2). The incidence of mediastinal tumors is not high; however, a huge mediastinal tumor's surgical risk is easily ignored, especially concerning the anesthesia required for the resection surgery. During tumor resection, blood pressure drops and heart rate changes often occur due to the squeezing and pulling of the heart and blood vessels. The unbalanced ventilation and blood flow ratio, resulting in a decreased peripheral oxygen saturation, make anesthesia management more complicated and difficult. Thus, adequate preoperative evaluation and preparation are necessary (3).

In recent years, cinematic rendering (CR), which is a new technology for the post-processing of medical image data, has been introduced in preclinical practice (4). By using a different lighting model than traditional three-dimensional (3D) methods, CR takes direct and indirect illumination into account when constructing an image and thus achieves a higher rendering quality $(5,6)$. With its unprecedented degree of realism, CR has begun to be used as a new method for visualizing vascular structures in complex anatomical regions (4). The potential advantages of CR images in understanding the complicated structure of mediastinal vessels, mediastinal tumors, and other anatomical structures have been highlighted in the literature (7) Given the anatomic complexity of mediastinal tumors, which have many adjacent vascular structures, CR has inherent advantages relative to other $3 \mathrm{D}$ methods (such as traditional volume rendering and multiplanar reformatting) in accurately displaying those position structures. Further, CR can be more intuitively grasped than less photorealistic depictions (7).

The Ethics Committee of the Yunnan Cancer Hospital approved and supervised the patient images used in this study. A 38-year-old woman was admitted to our hospital due to chest pain, which she stated she had been experiencing for the last half month (Figure 1). Five days earlier, the patient had been diagnosed with a left anterior mediastinal tumor. A computed tomography (CT) examination showed a large cystic, solid mass in the anterior mediastinum, approximately $20 \mathrm{~cm} \times 17 \mathrm{~cm} \times 12 \mathrm{~cm}$ in size, mainly composed of cystic components. The lesion pushed the trachea and mediastinum to the right, and the main pulmonary artery and left trunk were compressed and narrowed. Thoracic surgeons planned to remove the huge mediastinal tumor, and the operation went smoothly.

In this case, in which the patient had a huge mediastinal tumor, CR generated realistic images that depicted the anatomical structure (including the muscle, bone, and blood vessels) in great detail. Such detail is very helpful in preoperative operation and management planning. Generally, in a preoperative evaluation of giant mediastinal tumors, the thoracic surgeon should not only pay attention 

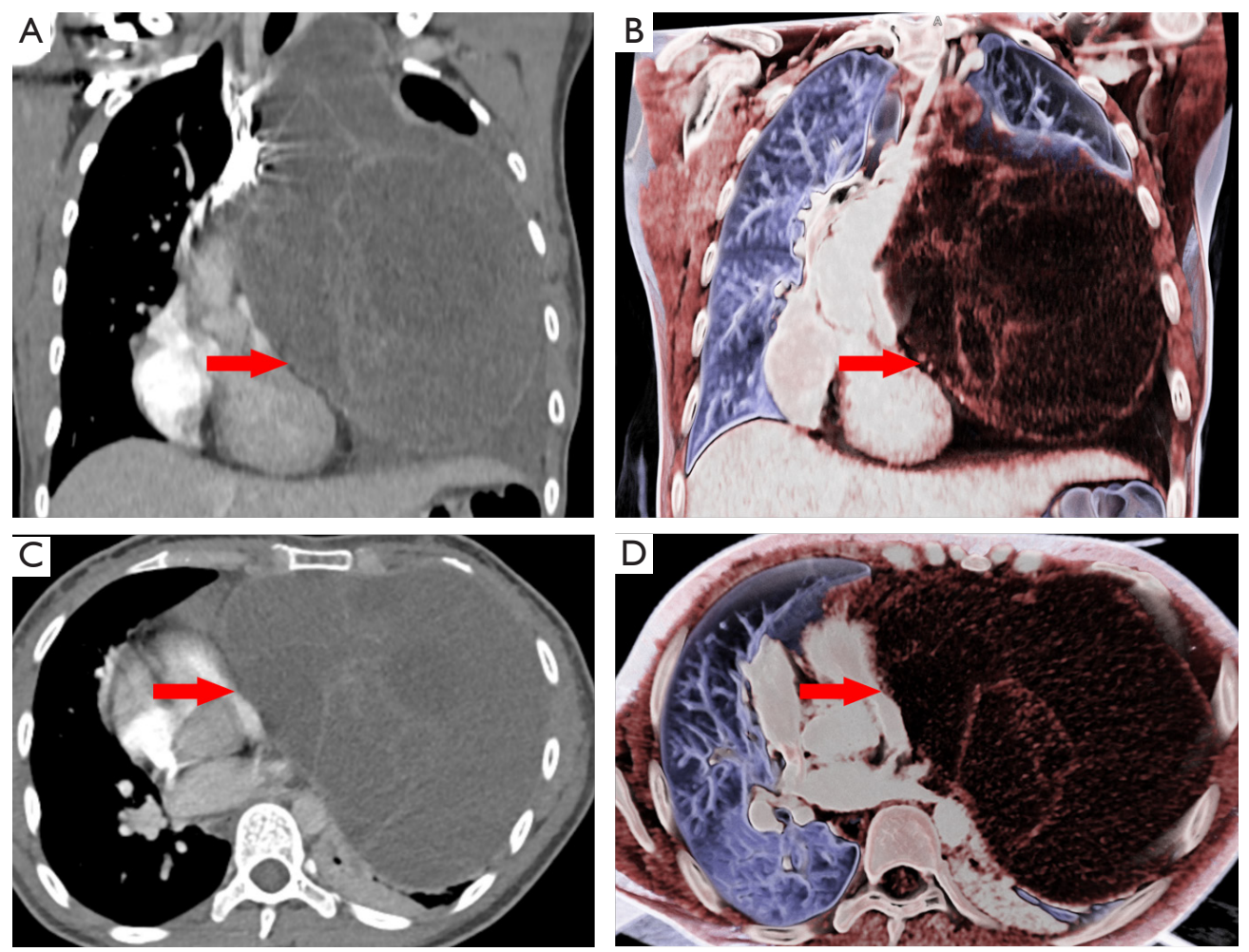

Figure 1 Preoperative imaging data of the patient. The coronal- (A) and axial- (C) enhanced CT images of the mediastinal window show the compression of the mass on the trachea and cardiac vessels. The CR images (B,D) clearly shows the relationship between the mass and the cardiovascular, trachea, and lung. The red arrow indicates a large mass in the mediastinum. CT, computed tomography; CR, cinematic rendering.

to the tumor, airways, and chest but should also carefully consider which surgical method is the most appropriate, depending on the tumor size, the attachment position of the stalk and the tumor, and the risk of airway impact both during surgery and before anesthesia (8). Thus, detailed imaging studies of mediastinal tumors of patients are necessary for anesthesia planning. Concerning CR, this new technology can provide important information that may inform disease identification, characterization, and treatment planning. It is worth noting that the main limitations of CR are operator dependency and variability, as embodied in the fact that CR requires a more powerful processor and longer processing time.

Further, one disadvantage of $\mathrm{CR}$ is that some mediastinal structures may appear as nodules. Similar studies need to be conducted to provide a more objective evaluation of this new technology. However, realistic CR images may become an indispensable tool for preoperative evaluation and surgical planning.

\section{Acknowledgments}

Rui Wang would especially like to thank his parents Chao Wang and Huaner Wei, for their continuous encouragement and support during his academic endeavors. Funding: None.

\section{Footnote}

Conflicts of Interest: All of the authors have completed the ICMJE uniform disclosure form (available at http://dx.doi. org/10.21037/qims-20-1161). The authors have no conflicts of interest to declare.

Ethical Statement: The authors are accountable for all aspects of the work in ensuring that questions related to the accuracy or integrity of any part of the work are appropriately investigated and resolved. The Ethics Committee approved the study of the Yunnan Cancer 
Hospital, and informed consent was obtained from the individual participant.

Open Access Statement: This is an Open Access article distributed in accordance with the Creative Commons Attribution-NonCommercial-NoDerivs 4.0 International License (CC BY-NC-ND 4.0), which permits the noncommercial replication and distribution of the article with the strict proviso that no changes or edits are made and the original work is properly cited (including links to both the formal publication through the relevant DOI and the license). See: https://creativecommons.org/licenses/by-nc-nd/4.0/.

\section{References}

1. Rabiou S, Lakranbi M, Ghizlane T, Elfatemi H, Serraj M, Ouadnouni Y, Smahi M. Which surgery for mediastinum tumor: Experience of the Department of thoracic surgery of CHU Hassan II of Fès. Rev Pneumol Clin 2017;73:246-52.

2. Shahrzad M, Le TS, Silva M, Bankier AA, Eisenberg

Cite this article as: Wang R, Li JY. A preoperative evaluation of a giant mediastinal tumor using a novel three-dimensional cinematic rendering visualization method. Quant Imaging Med Surg 2021;11(11):4700-4702. doi: 10.21037/qims-20-1161
RL. Anterior mediastinal masses. AJR Am J Roentgenol 2014;203:W128-38.

3. Gothard JW. Anesthetic considerations for patients with anterior mediastinal masses. Anesthesiol Clin 2008;26:305-14.

4. Caton MT Jr, Wiggins WF, Nunez D. Three-Dimensional Cinematic Rendering to Optimize Visualization of Cerebrovascular Anatomy and Disease in CT Angiography. J Neuroimaging 2020;30:286-96.

5. Soyer P. Cinematic rendering: When virtuality comes true. Diagn Interv Imaging 2019;100:465-6.

6. Chu LC, Rowe SP, Fishman EK. Cinematic rendering of focal liver masses. Diagn Interv Imaging 2019;100:467-76.

7. Rowe SP, Zimmerman SL, Johnson PT, Fishman EK. Evaluation of Kawasaki's disease-associated coronary artery aneurysms with 3D CT cinematic rendering. Emerg Radiol 2018;25:449-53.

8. Liu CH, Chang HC, Goan YG. Large pedunculated lipoma of the esophagus. J Formos Med Assoc 2008;107:424-7. 